\title{
On-Chip Integrated Silicon Bulk-Micromachined Soil Moisture Sensor Based on the DPHP Method
}

\author{
A.Valente*, C. Couto** and J.H. Correia** \\ *ICETA- University of Trás-os-Montes and Alto Douro, Dep. Engenharias, \\ P-5000 Vila Real, Portugal, avalente@utad.pt \\ **University of Minho, Industrial Electronics Dep., P-4800 Azurém, Guimarães, Portugal
}

\begin{abstract}
SUMMARY
This paper reports the design, modelling, fabrication and assembly of a silicon bulk-micromachined soil moisture microsensor using the Dual-Probe Heat-Pulse (DPHP) method. Soil humidity measurement is essential to study soil preservation and control the development of plants, namely in closed ecosystem. The DPHP method uses a heater (Peltier effect) and a temperature probe (Seebeck effect) to determine the volumetric heat capacity of the soil and hence water content $\left(\theta_{v}\right)$. This is the first time that the DPHP method is implemented in a microdevice and the first integrated sensor for soil moisture. This microdevice is more suited to measure at different soil depths in a non-destructive and automated manner.
\end{abstract}

Keywords: Soil moisture sensor, integrated microsensor, soil water content, heat capacity sensor.

\section{INTRODUCTION}

The need to determine the amount of water contained in the soil arises frequently in many agronomic, ecological, and hydrological investigations. The aim is to understand the soil's chemical, mechanical, hydrological, and biological relationships. Today, a large number of sensors, based on different methods: nuclear, electromagnetic, tensiometric, capacitance, are available for measuring soil moisture. Generally, these methods have several limitations that restrict their integration in irrigation systems. Among others, the main disadvantages are: soil dependency, inaccuracy and high cost.

Time domain reflectometer (TDR) sensors, which are based on the influence of soil water content over the propagation of electromagnetic waves, are independent of soil texture, temperature and salt content, but its high cost restricts the applicability to these systems [1-2]. Therefore, the development of a low-cost miniaturised system with electronics, network solution and external communications for allowing its implantation next to the plant roots, will be a breakthrough.
The same basic fabrication concepts and materials, which have made microelectronics successful, are now being adapted to making low-cost, small, highperformance sensor systems devices, e.g. a silicon bulkmicromachined soil moisture sensor. The compatibility with CMOS standard fabrication processing allows integration of the sensor and electronics in the same chip. The DPHP sensor is about $30 \mathrm{~mm}$ long $\times 6 \mathrm{~mm}$ wide $\mathrm{x} 0.8 \mathrm{~mm}$ in height; the probe pitch is $3 \mathrm{~mm}$ for allowing small-scale spatial measurements of $\theta_{v}$, which can be made near the soil surface where large root densities are found.

\section{THEORY}

The heat capacity of soil, $\rho c_{p}$, is evaluated by adding the volumetric heat capacities of the soil constituents:

$$
\rho c_{p}=1.92 X_{m}+2.51 X_{o}+4.18 \theta_{v}
$$

where $X_{m}, X_{o}$, and $\theta_{v}$ are the mineral, organic, and water fractions of the soil, respectively. The leading coefficients represent the volumetric heat capacity $\left(\mathrm{MJm}^{-30} \mathrm{C}^{-1}\right)$ of each soil constituent. When the pulse of heat is applied during a fixed interval of time to the line source (heater probe), the maximum rise in temperature $\left(\Delta T_{m}\right)$ at some distance from the line source is measured (temperature probe). The relationship between the $\rho c_{p}$ and $\Delta T_{m}$ is, [3]

$$
\rho c_{p}=\frac{q}{e \pi r^{2} \Delta T_{m}}
$$

where, $q\left(\mathrm{Jm}^{-1}\right)$ is the heat applied per unit length of the line source, $e$ is the base of natural logarithms, and $r(\mathrm{~m})$ is the distance between the heat and temperature probes. The use of this model requires the assumptions: (i) that the finite heater is closed to an infinitely long heater, (ii) that the cylindrical heater approximated a line source of heat, and (iii) that the short-duration heating approximated an instantaneous release of heat. Providing, that (i) the ratio of heater half-length to 
temperature probe spacing $(b / r)$ is greater than to 2.5, we could assume $(0.14 \%$ error $)$ that the probe heater is infinite. In addition, (ii) the ratio of heater radius to temperature probe spacing $(a / r)$ is less than 0.06 , and (iii) the heating duration is less than $8 \mathrm{~s}$, we minimize the errors and support the use of Campbell model (2) as a model for determining heat capacity [4]. Substituting Eq. (1) into Eq. (2) and rearranging yields an expression that shows the relationship between $\theta_{v}$ and $\Delta \mathrm{Tm}$,

$$
\theta_{v}=\frac{\frac{q}{e \pi r^{2} \Delta T_{m}}-\left(1.92 X_{m}+2.50 X_{o}\right)}{4.18}
$$

or,

$$
\Delta T_{m}=\frac{q}{e \pi r^{2}\left(1.92 X_{m}+2.50 X_{o}+4.18 \theta_{v}\right)}
$$

Although $\Delta T_{m}$ varies with $\rho c_{p}$ and $\theta_{v}, q$ can be selected to produce an adequate temperature signal for the expected range of $\theta_{v}$ for a typical agricultural soil $(0.05$ to $\left.0.35 \mathrm{~m}^{3} \mathrm{~m}^{-3}\right)$. The Fig. 1 shows that a $q$ value of $50 \mathrm{Jm}^{-1}$ produces a span of $0.5{ }^{\circ} \mathrm{C}$ over the entire range of $\theta_{v}$, while for $q=200 \mathrm{Jm}^{-1}$ the span is about $1.5^{\circ} \mathrm{C}$.

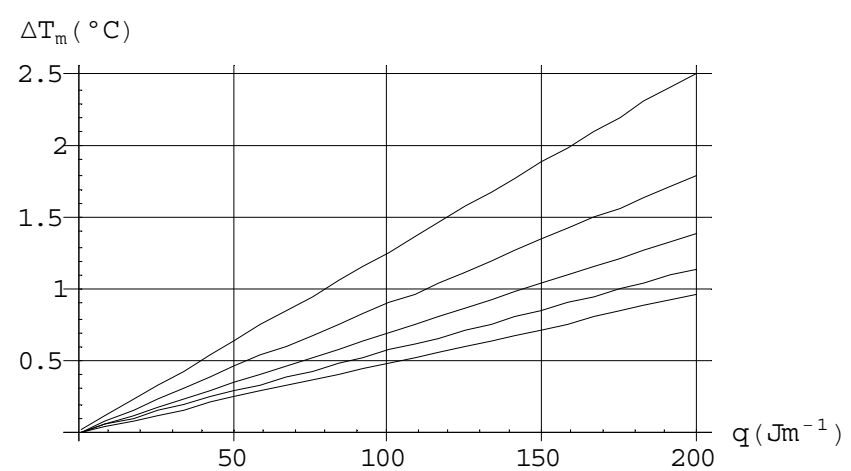

Fig. 1: Variation of temperature for different values of heat applied in a typical agricultural soil.

Minor value of $q$ implies less current consumption but also less signal to noise ratio. The partial derivate of $\Delta T_{m}$ with respect to $\theta_{v}$ yields an expression of the sensitivity of the temperature rise with respect to the change in soil water content:

$$
\frac{\partial \Delta T m}{\partial \theta_{v}}=\frac{-4.18 q}{e \pi r^{2}\left(1.92 X_{m}+2.50 X_{o}+4.18 \theta_{v}\right)^{2}}
$$

Figure 2 shows the relationship between the three factors stated in the above equation for typical agricultural soil.

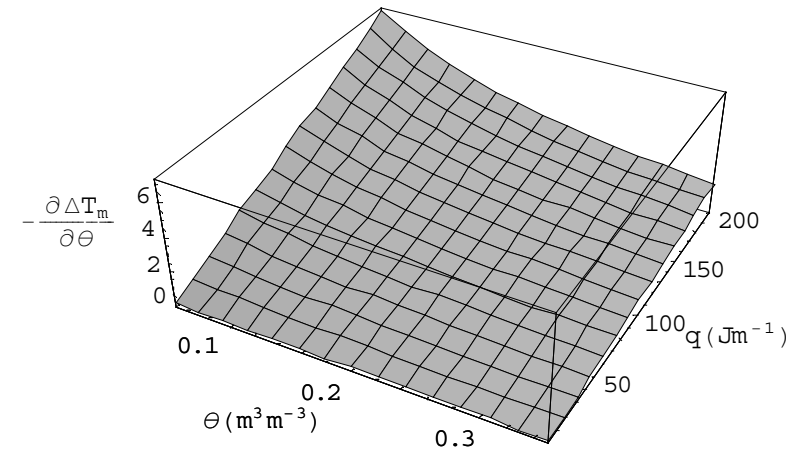

Fig. 2: Temperature sensitivity vs. heat applied by soil water content in a typical agricultural soil.

If one considers that range of water content and the common sensitivities of integrated thermopiles to be $50 \mathrm{mV} /{ }^{\circ} \mathrm{C}$ [5] then a $1 \%$ change in $\theta_{v}$ would cause a change in the electrical signal depending on $q$ (Fig.3). Sensitivity of $\Delta T_{m}$ decreases as less energy is applied to the probe $(q)$, so the use of less supply will imply the need to use $A / D$ converter with more resolution to maintain accuracy. Previous studies show that a minimum of $0.5^{\circ} \mathrm{C}$ for $\Delta T_{m}$ is a good choice [6].

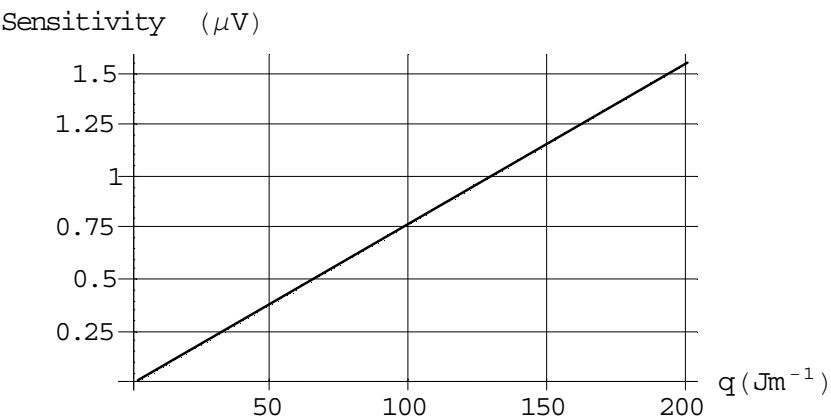

Fig. 3: Sensitivity considering variation of $1 \%$ in soil water content.

This implies (Fig.1) that a good value for $q$ will be $100 \mathrm{Jm}^{-1}$ with a sensitivity (Fig. 3 ) of $0.75 \mu \mathrm{V}$. Since,

$$
q=\left(\frac{V}{R}\right)^{2} \times \rho \times t
$$

were $t$ is the heat-pulse duration, $V$ the voltage applied to the heater, $R$ the heater resistance and $\rho$ is the heater 
resistivity, then $q$ can be controlled by pulse duration and/or voltage.

\section{EXPERIMENTS}

The heat-pulse macro device used in this study to test the DPHP method is illustrated schematically in Fig. 4.

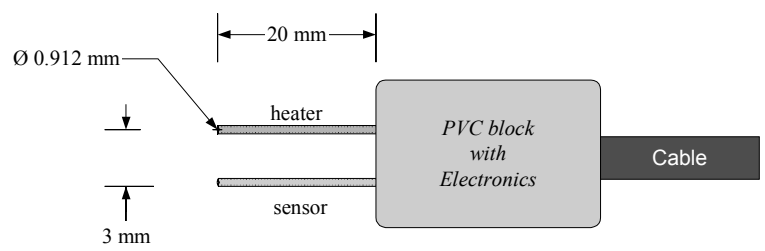

Fig. 4: Sketch of the soil moisture macrosensor

It consists of two needle probes mounted in parallel to provide a heater and a sensor probe, as reported by [7-8]. The needles were made from stainless steel tubing, $0.912 \mathrm{~mm}$ in diameter, which protrude $20 \mathrm{~mm}$ beyond the edge of the acrylic mounting. Spacing is 3 $\mathrm{mm}$ between the heater and the sensor probe.

The heater was made from enameled Stablohm 800 A wire $\left(0.062 \mathrm{~mm}\right.$ diameter and $440.8 \Omega \mathrm{m}^{-1}$ of resistivity) which was pulled into the heater needle. The heater resistance is $68.5 \Omega$. Copper-constantan thermocouple was pulled into and centered in the sensor needle. The needles were then filled with high-thermal-conductivity epoxy glue to provide water-resistant, electrically insulated probes.

The heat pulse was generated by applying voltage $(11.5 \mathrm{~V})$ from a direct current supply to the heater for a fixed period $(8 \mathrm{~s})$. This gave a nominal value for $\mathrm{q}$ of $100 \mathrm{Jm}^{-1}\left[(10.5 \mathrm{~V} / 68.5 \Omega)^{2} \cdot 440.8 \Omega \mathrm{m}^{-1} \cdot 8 \mathrm{~s}\right]$. A data acquisition system based on a micro-controller and a sigma-delta ADC, controlled the heat pulse, monitored the current through the heater, measured the temperature of the thermocouple, and recorded the average power and the maximum temperature.

Soil samples of Almendra silt loam, which were wet to a predetermined water content and mixed, were packed into a cylinder $77 \mathrm{~mm}$ in diameter by $70 \mathrm{~mm}$ long, with the soil moisture macro sensor at the center. Measurements were taken and then the soil was weighed and dried at $105{ }^{\circ} \mathrm{C}$ for $24 \mathrm{~h}$ to determine bulk density and water content (thermo--gravimetric method),

$$
\theta=\frac{(\text { wet weight })-(\text { dryweight })}{\text { dryweight }}
$$

\section{RESULTS}

Table 1 lists the thermo-gravimetric soil water content $\left(\theta_{g}\right)$ and the measured values; maximum temperature rise $\left(\Delta T_{m}\right)$ and the heat applied per unit length of the line source $(q)$.

Table 1: Soil water contents calculated using Eq.3.

\begin{tabular}{cccc}
\hline \hline $\boldsymbol{\theta}_{\boldsymbol{g}}\left(\boldsymbol{m}^{3} \boldsymbol{m}^{-3}\right)$ & $\boldsymbol{\Delta \boldsymbol { T } _ { \boldsymbol { m } } ( { } ^ { \mathbf { 0 } } \mathbf { C } )}$ & $\boldsymbol{q}\left(\mathbf{J m}^{\mathbf{- 1}}\right)$ & $\boldsymbol{\theta}_{\boldsymbol{v}}\left(\boldsymbol{m}^{3} \boldsymbol{m}^{-3}\right)$ \\
\hline 0 & 1.25 & 100 & 0 \\
0.1 & 0.88 & 100 & 0.106 \\
0.2 & 0.71 & 100 & 0.190 \\
0.3 & 0.56 & 100 & 0.308 \\
0.4 & 0.48 & 100 & 0.401 \\
\hline \hline
\end{tabular}

In soils with low organic matter, such as Almendra, $X_{o}$ is neglected. The value of $X_{m}$ is determined by dividing the soil bulk density by the particle density. An average value of $2.65 \mathrm{Mgm}^{-3}$ is often used for particle density of soils. Therefore, using Eq. 3 the calculated values $\left(\theta_{v}\right)$ of soil water content are in good agreement with thermo-gravimetric values.

Figure 5 shows typical temperature by time data for heat-pulse measurements.

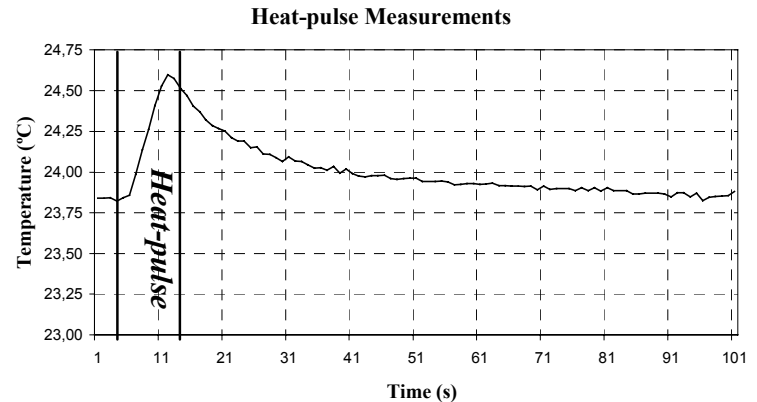

Fig. 5:Typical temperature by time data obtained for $0.1 \mathrm{~m}^{3} \mathrm{~m}^{-3}$ of volumetric water content and a heat-pulse of $8 \mathrm{~s}$

\section{DISCUSSION}

Figure 6 shows the designed sensor. The sensor is implemented in a post-processing step (silicon bulk-micromachining with $\mathrm{KOH}$ as etchant) after a CMOS standard process for the fabrication of readout electronics [9]. 


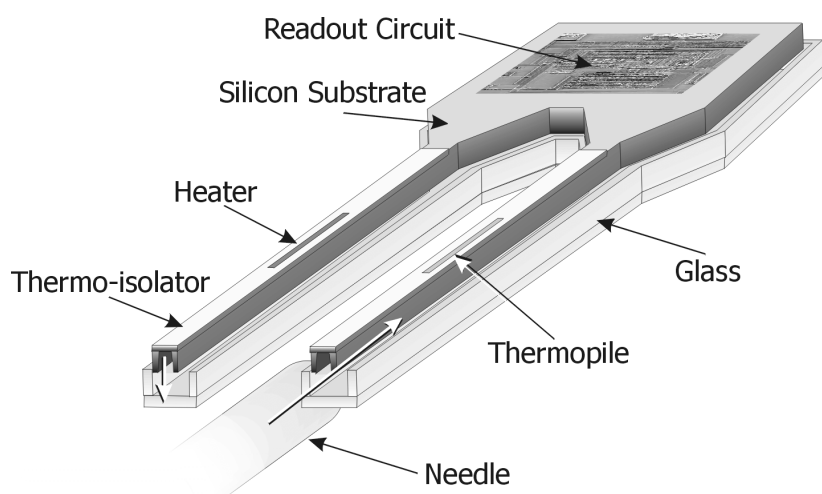

Fig. 6: The designed soil moisture sensor with readout electronics.

Silicon has a large thermal conductivity (about $156 \mathrm{Wm}^{-1} \mathrm{~K}^{-1}$ ) and produces a thermal short-circuit between the heater-probe and the temperature-probe. High-performance thermoelectric sensors require a proper insulation between the 'hot' and 'cold' junction of the thermocouples. Therefore, silicon dioxide and silicon nitride (low thermal conductivity, 2 to $3 \mathrm{Wm}^{-1} \mathrm{~K}^{-1}$ ) are used for embedding the probes. A thermal isolator glass is used in the packaging of the probes.

Needles are then inserted into the heater and sensor probes and then filled with high-thermal-conductivity epoxy glue. The upper part of the sensor (the readout circuit) is filled with a very low thermal conductivity epoxy glue to provide water resistance and electrical insulation.

\section{CONCLUSIONS}

The design, modelling, fabrication and assembly of a silicon bulk-micromachined soil moisture microsensor using the Dual-Probe Heat-Pulse (DPHP) method was achieved. The DPHP method showed to be the most appropriate to measure humidity at different soil depths, and therefore, close to the surface of the soil in a nondestructive and automated manner. This is the first time that the DPHP method is implemented in a microdevice and the first integrated sensor for soil moisture. The DPHP sensor is about $30 \mathrm{~mm}$ long by $6 \mathrm{~mm}$ wide by $0.8 \mathrm{~mm}$ in height; the probe pitch is $3 \mathrm{~mm}$ for allowing small-scale spatial measurements of $\theta_{v}$, which can be made near the soil surface where large root densities are found. The fabrication of the first prototype is running.

\section{ACKNOWLEDGMENTS}

The authors wish to acknowledge the Agricultural and Agro-industrial Science and Technology Institute of the University of Trás-os-Montes and Alto Douro that partially sponsored this work.

\section{REFERENCES}

[1] C. G. Topp, J. L. Davis and A. P. Annan, "Electromagnetic determination of soil water content using TDR: Measurements in coaxial transmission lines." Water Resour. Res., vol. 16, pp.574-582, 1980.

[2] C. G. Topp, J. L. Davis "Measurement of soil water content using time-domain reflectometry (TDR): A field evaluation", Soil Sci. Soc. Am. J., vol. 49, pp. 19-24, 1985.

[3] G.S. Campbell, C. Calissendorff, and J.H. Williams, "Probe for measuring soil specific heat using a heat-pulse method", Soil Sci. Soc. Am. J., vol.55, pp. 291-293, 1991.

[4] G.J. Kluitenberg, J.M. Ham, and K.L. Bristow, "Error analysis of the heat pulse method for measuring soil volumetric heat capacity”, Soil Sci. Soc. Am. J., vol. 57, pp. 1444-1451, 1993.

[5] A.W. van Herwaarden, D.C. van Duyn, B.W. van Oudheusden, and P.M. Sarro, "Integrated Thermopile Sensors", Sensors and Actuators, A21A23, pp. 621-630, 1989.

[6] J.R. Bilskie, "Dual probe methods for determining soil thermal properties: Numerical and laboratory study", Ph.D. diss. Iowa State Univ., Ames (Diss. Abstr. 9503532), 1994.

[7] Julie M. Tarara and Jay M. Ham, "Measuring soil water content in the laboratory and field with dualprobe heat-capacity sensors", Agronomy Journal, vol. 89, pp. 535-542, 1997.

[8] Y. Song, J.M. Ham, M.B. Kirkham, and G.J. Kluitenberg, "Measuring soil water content under turfgrass using the dual-probe heat-pulse technique", J. Amer. Soc. Hort. Sci., 123(5), pp. 937-941, 1998.

[9] J.H.Correia, G. de Graaf, S. H. Kong, M. Bartek, R. F. Wolffenbuttel, "Single-chip CMOS optical microspectrometer", Transducers'99, Sendai, Japan, pp. 896-899, 1999. 